\title{
Sintesis MOF Biner UiO-66/HKUST-1 dengan Metode Solvotermal
}

\author{
Liyana Labiba Zulfa, Ratna Ediati, dan Yuly Kusumawati \\ Departemen Kimia, Fakultas Sains, Institut Tekologi Sepuluh Nopember (ITS) \\ e-mail: ratna.ediati@gmail.com
}

\begin{abstract}
Abstrak-Padatan HKUST-1, UiO-66, dan MOF biner UiO66/HKUST-1 telah berhasil disintesis menggunakan metode solvotermal secara one pot process. Sintesis padatan MOF biner UiO-66/HKUST-1 dilakukan dengan penambahan variasi jumlah UiO-66 sebesar 5, 10, dan $20 \%$ terhadap jumlah HKUST-1. Padatan hasil sintesis dikarakterisasi menggunakan instrumen XRD, FTIR dan SEM. Difraktogram hasil sintesis memiliki puncak karakteristik pada $2 \theta=6,7^{\circ} ; 9,5^{\circ} ; 11^{\circ}, 54^{\circ}$; dan $19^{\circ}$ untuk padatan HKUST-1; $7,34^{\circ}, 8,3^{\circ}$ dan $25,6^{\circ}$ untuk padatan UiO-66; $6,64^{\circ}, 7,18^{\circ}, 9,36^{\circ}, 11,5^{\circ}$ dan $18,9^{\circ}$ untuk padatan MOF biner. Analisa FTIR menunjukkan bahwa MOF biner hasil sintesis memiliki daerah serapan yang sama dengan padatan HKUST-1 dan UiO-66. Mikrograf MOF Biner hasil sintesis menunjukkan terdapat perpaduan morfologi antara HKUST-1 dan UiO-66.
\end{abstract}

Kata Kunci-HKUST-1, MOF biner UiO-66/HKUST-1, Solvotermal.

\section{PENDAHULUAN}

$M$ etal Organic Framework (MOF) merupakan senyawa hibrida anorganik-organik yang terbentuk dari ion logam dan ligan organik melalui ikatan koordinasi [1]. Variasi logam dan ligan organik yang digunakan menghasilkan Metal Organic Framework (MOF) dengan sifat kimia, struktur, dan topografi yang berbeda-beda, sehingga Metal Organic Framework (MOF) memiliki keunggulan dan keunikan dibandingkan material berpori lainnya. Pada umumnya MOF memiliki (i) luas permukaan yang besar, (ii) porositas yang tinggi, (iii) struktur yang bervariasi, dan (iv) ukuran pori yang teratur [2]. Ukuran dan volume pori pada Metal Organic Framework (MOF) dapat disesuaikan terhadap aplikasi dari Metal Organic Framework (MOF). Metal Organic Framework (MOF) banyak digunakan sebagai katalisis, adsorben, serta template padatan [1].

Salah satu MOF yang sering digunakan sebagai adsorben adalah HKUST-1 (Hongkong University Of Science And Technology - 1). Besarnya luas permukaan dan keteraturan pori yang dimiliki oleh HKUST-1 menjadikannya sebagai adsorben yang selektif. Namun, HKUST-1 memiliki pori berukuran mikro yang dapat menghambat laju difusi pada proses adsorpsi. Peningkatan ukuran pori dapat dilakukan melalui penambahan logam atau senyawa mesopori pada MOF [3]. Penelitian sebelumnya menyebutkan bahwa penambahan senyawa mesopori jenis polioksometalat $\left(\mathrm{H}_{6} \mathrm{P}_{2} \mathrm{~W}_{19} \mathrm{O}_{62}\right)$ pada HKUST-1 meningkatkan luas permukaan dan ukuran pori komposit yang dihasilkan dibandingkan HKUST-1 murni [4]. Hal ini dapat membantu meningkatkan kinerjanya sebagai adsorben maupun katalis.

Baru-baru ini, [5] dan [6] melaporkan tentang sintesis MOF biner untuk meningkakan ukuran pori dari MOF. Berdasarkan uraian diatas, maka pada penelitian ini dilakukan sintesis MOF biner UiO-66/HKUST-1 secara solvotermal.

\section{METODOLOGI PENELITIAN}

\section{A. Sintesis HKUST-1, UiO-66 dan MOF Biner UiO-} 66/HKUST-1

HKUST-1 disintesis mengikuti prosedur yang dilaporkan oleh Chowdhury dan kawan-kawan [7]. Sintesis HKUST-1 dimulai dengan melarutkan 2,077 g Cu( $\left.\mathrm{NO}_{3}\right)_{2} \cdot 3 \mathrm{H}_{2} \mathrm{O}$ dalam $15 \mathrm{~mL}$ aqua DM sedangkan $1 \mathrm{~g}$ BTC dilarutkan dalam 30 $\mathrm{mL}$ campuran etanol dan DMF dalam botol duran terpisah. Masing-masing larutan diaduk menggunakan pengaduk magnetik selama 30 menit. Campuran reaksi dipanaskan dalam oven pada suhu $100{ }^{\circ} \mathrm{C}$ selama 10 jam, kemudian didinginkan pada suhu kamar selama dua hari setelah itu dilanjutkan dengan dekantasi. Endapan yang dihasilkan dicuci menggunakan $40 \mathrm{~mL}$ DMF kemudian direndam selama semalam setelah itu dilanjutkan dengan dekantasi. Metode pencucian diulangi menggunakan $60 \mathrm{~mL}$ metanol dalam penangas minyak pada suhu berkisar $40{ }^{\circ} \mathrm{C}-55^{\circ} \mathrm{C}$ selama 72 jam. Endapan yang dihasilkan dikeringkan dalam oven pada suhu $55^{\circ} \mathrm{C}$ selama 4 jam.

UiO-66 disintesis mengikuti prosedur yang dilaporkan oleh Azhar dan kawan-kawan [5]. Sintesis UiO-66 dimulai dengan melarutkan 0,3496 $\mathrm{g} \mathrm{ZrCl}_{4}$ dalam $15 \mathrm{~mL}$ DMF sedangkan 0,2492 $\mathrm{g} \mathrm{H}_{2} \mathrm{BDC}$ dilarutkan dalam $15 \mathrm{~mL}$ DMF dalam botol duran terpisah. Masing-masing larutan diaduk menggunakan pengaduk magnetik selama 30 menit. Campuran reaksi dipanaskan dalam oven pada suhu $120{ }^{\circ} \mathrm{C}$ selama 24 jam kemudian didinginkan pada suhu kamar selama semalam dilanjutkan dengan dekantasi. Endapan yang dihasilkan dicuci menggunakan $40 \mathrm{~mL}$ DMF kemudian didekantasi kembali. Metode pencucian diulangi menggunakan $30 \mathrm{~mL}$ kloroform. Endapan yang dihasilkan dikeringkan dalam oven pada suhu $60^{\circ} \mathrm{C}$ selama 4 jam.

Sintesis MOF biner UiO-66/HKUST-1 memiliki metode hampir sama dengan sintesis HKUST-1 dan UiO-66. UiO66 yang telah dipanaskan dalam oven pada $120{ }^{\circ} \mathrm{C}$ selama 24 jam ditambahkan ke dalam prekursor HKUST-1. Selanjutnya, metode sintesis serupa dengan metode sintesis HKUST-1.

\section{B. Karakterisasi Padatan Hasil Sintesis}

Masing-masing padatan hasil sintesis dikarakterisasi menggunakan instrumen X-Ray Diffraction (XRD), Fourier Transform Infra Red (FTIR), dan Scanning Electron Microscope (SEM).

\section{HASIL DAN DISKUSI}

\section{A. Hasil Sintesis HKUST-1, UiO-66, dan MOF Biner UiO-} 66/HKUST-1

Sintesis padatan HKUST-1 dan UiO-66 dilakukan menggunakan metode solvotermal sedangkan padatan MOF biner UiO-66/HKUST-1 menggunakan one pot process. Padatan HKUST-1 hasil sintesis berwarna biru cerah yang memiliki kesamaan dengan penelitian sebelumnya [7]. 
Padatan UiO-66 hasil sintesis berwarna putih yang memiliki kesamaan dengan penelitian sebelumnya [5]. Padatan MOF biner UiO-66/HKUST-1 variasi 5\% selanjutnya disebut UH (5), MOF biner UiO-66/HKUST-1 variasi $10 \%$ selanjutnya disebut UH (10), dan MOF biner UiO-66/HKUST-1 variasi 20\% selanjutnya disebut UH (20) hasil sintesis berwarna biru yang memiliki kesamaan dengan penelitian sebelumnya [5]. Massa padatan hasil sintesis ditunjukkan pada Tabel 1.

Tabel 1.

Massa padatan hasil sintesis

\begin{tabular}{ll}
\multicolumn{2}{c}{ Massa padatan hasil sintesis } \\
\hline \hline Sampel & Massa (gram) \\
\hline HKUST-1 & 2,2129 \\
UiO-66 & 0,3 \\
UH (5) & 2,0290 \\
UH (10) & 2,2070 \\
UH (20) & 2,4174 \\
\hline \hline
\end{tabular}

Berdasarkan pada Tabel 1, terlihat bahwa semakin banyak penambahan jumlah UiO-66 massa padatan MOF biner yang dihasilkan semakin bertambah.

\section{B. Karakterisasi Padatan Hasil Sintesis}

\section{1) B.1 Hasil Karakterisasi Difraksi Sinar-X (XRD)}

Hasil difraktogram padatan hasil sintesis ditunjukkan pada Gambar. 1 .

Difraktogram padatan HKUST-1 hasil sintesis memiliki puncak karakteristik pada daerah $2 \theta=6,7^{\circ} ; 9,5^{\circ} ; 11,54^{\circ}$; dan $19^{\circ}$. Difraktogram padatan HKUST-1 hasil sintesis sesuai dengan penelitian yang telah dilakukan sebelumnya [8] yaitu puncak pada daerah $6,7^{\circ}$ dan $9,5^{\circ}$ dengan intensitas sedang; puncak utama yang khas pada daerah $11,5^{\circ}$ dengan intensitas tertinggi; puncak karakteristik lainnya pada daerah $13,4^{\circ}$ dengan intensitas lemah.

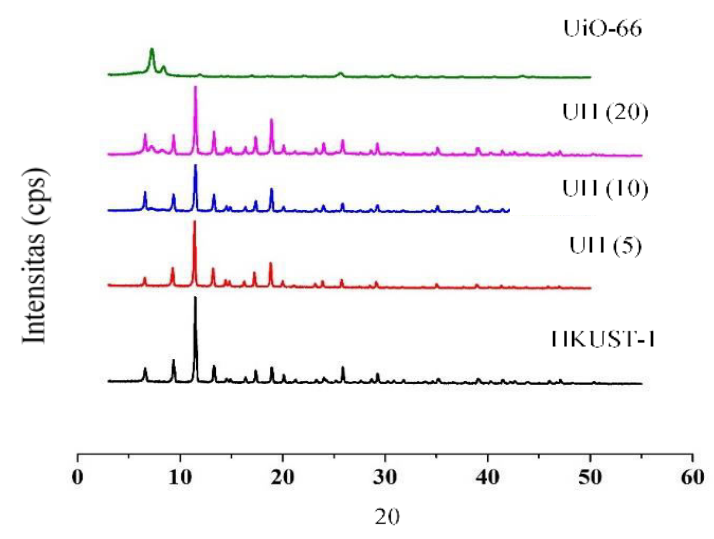

Gambar 1. Difraktogram padatan hasil sintesis.

Difraktogram UiO-66 hasil sintesis memiliki puncak karakteristik pada $2 \theta=7,34^{\circ} ; 8,3^{\circ}$ dan $25,6^{\circ}$. Puncak karakteristik UiO-66 hasil sintesis sesuai dengan pola difraksi yang telah disintesis sebelumnya [9] yaitu puncak yang muncul adalah $7,3^{\circ}$ sebagai puncak karakteristik serta beberapa puncak lainnya yang muncul pada daerah $2 \theta=$ $8,4^{\circ}$ dan $25,6^{\circ}$. Difraktogram MOF biner hasil sintesis memiliki puncak karakteristik pada $2 \theta=11,5^{\circ}$, serta beberapa puncak lainnya pada daerah $2 \theta=6,64^{\circ} ; 9,36^{\circ}$; dan $18,9^{\circ}$. Puncak karakteristik tersebut menandakan terdapatnya padatan HKUST-1 dalam MOF biner hasil sintesis. Puncak karakteristik UiO-66 juga terdapat dalam difraktogram hasil sintesis namun dengan intensitas rendah yaitu $2 \theta=7,18^{\circ}$.

\section{2) Hasil Karakterisasi Fourier Transform Infra Red (FTIR)}

Hasil karakterisasi spektra FTIR padatan hasil sintesis ditunjukkan pada Gambar 2.

Spektra serapan padatan HKUST-1, UiO-66, dan MOF biner hasil sintesis menunjukkan pita serapan yang khas seperti terlihat pada Gambar 2. Daerah pita serapan yang lebar pada bilangan gelombang sekitar $2600-3500 \mathrm{~cm}^{-1}$ merupakan daerah serapan vibrasi ulur gugs $\mathrm{O}-\mathrm{H}$ dari karboksilat dalam $\mathrm{H}_{3} \mathrm{BTC}$ maupun $\mathrm{H}_{2} \mathrm{BDC}$. Pita serapan pada bilangan gelombang sekitar 1630 - $1660 \mathrm{~cm}^{-1}$ merupakan daerah serapan $\mathrm{C}=\mathrm{O}$ pada asam karboksilat dalam $\mathrm{H}_{3} \mathrm{BTC}$ maupun $\mathrm{H}_{2} \mathrm{BDC}$. Pita serapan pada bilangan gelombang sekitar 1450 - $1650 \mathrm{~cm}^{-1}$ merupakan daerah serapan vibrasi $\mathrm{C}=\mathrm{C}$ khas cincin aromatik yang terdapat dalam penghubung organik. Pita serapan pada bilangan gelombang sekitar $1400 \mathrm{~cm}^{-1}$ merupakan daerah serapan vibrasi ulur C-O dari asam karboksilat. Padatan HKUST-1 memiliki pita serapan yang khas pada bilangan gelombang $731,05 \mathrm{~cm}^{-1}$ yang menandakan terdapatnya vibrasi ulur dari $\mathrm{Cu}-\mathrm{O}$. Hal ini mendandakan bahwa telah terbentuk ikatan antara $\mathrm{Cu}$ dari atom pusat dengan $\mathrm{O}$ pada ligan organik [9]. Tidak adanya pita vibrasi pada daerah 410, 500, 610 dan $615 \mathrm{~cm}^{-1}$ menandakan padatan hasil sintesis telah bebas dari pengotor kristal $\mathrm{CuO}$ dan $\mathrm{Cu}_{2} \mathrm{O}$ selama proses nukleasi dari HKUST-1. Hal ini sesuai dengan hasil karakterisasi XRD yang menyatakan bahwa tidak terdapat pengotor $\mathrm{CuO}$ dan $\mathrm{Cu}_{2} \mathrm{O}$ pada padatan HKUST-1 dan MOF biner hasil sintesis. Padatan UiO-66 memiliki pita serapan yang khas pada bilangan gelombang $661,61 \mathrm{~cm}^{-1}$ yang menandakan terdapatnya vibrasi dari $\mathrm{Zr}-\mathrm{O}$. Hal ini mendandakan bahwa telah terbentuk ikatan antara $\mathrm{Zr}$ dari atom pusat dengan $\mathrm{O}$ pada ligan organik yang dipengaruhi oleh ikatan $\mathrm{C}-\mathrm{H}$ dan $\mathrm{O}-$ H [10]. Padatan UH (5), UH (10), dan UH (20) memiliki pita serapan pada bilangan gelombang $728 \mathrm{~cm}^{-1}$ merupakan vibrasi dari $\mathrm{Cu}-\mathrm{O}$ serta pita serapan pada bilangan gelombang sekitar $745 \mathrm{~cm}^{-1}$ merupakan vibrasi dari $\mathrm{Zr}-\mathrm{O}$. Puncak serapan pada MOF biner hasil sintesis sesuai dengan penelitian sebelumnya [5].

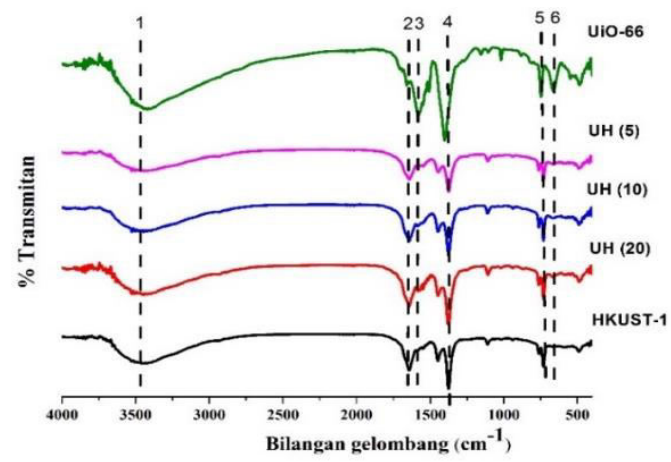

Gambar 2. Spektra FTIR padatan hasil sintesis.

\section{3) Hasil Karakterisasi Scanning Electron Microscope (SEM)}

Hasil karakterisasi SEM padatan hasil sintesis ditunjukkan pada Gambar 3.

Morfologi padatan HKUST-1 ditunjukkan pada Gambar 3.a memiliki bentuk oktahedral. Morfologi ini memiliki kesamaan dengan hasil penelitian yang telah dilakukan sebelumnya [7] menunjukkan bahwa sintesis HKUST-1 menggunakan pelarut air : DMF $:$ etanol $=1: 1: 1$ pada suhu $100{ }^{\circ} \mathrm{C}$ memiliki bentuk oktahedral dengan ukuran kistal yang seragam serta bentuk yang tajam pada setiap sisinya. 

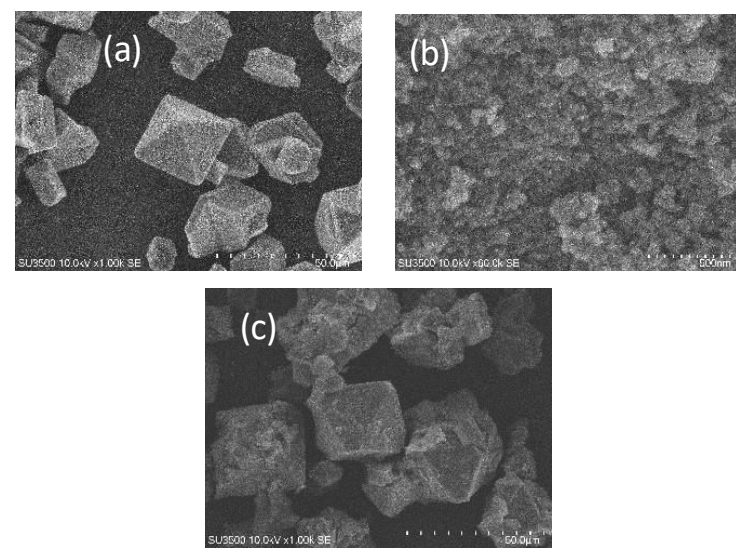

Gambar 3. Mikrograf (a) HKUST-1 (b) UiO-66 (c) MOF biner UiO66/HKUST-1 hasil sintesis.

Morfologi UiO-66 seperti ditunjukkan pada Gambar 3.b memiliki bentuk bulatan yang bergerombol. Morfologi ini memiliki kesamaan dengan hasil penelitian yang telah dilakukan sebelumnya [5] menunjukkan bahwa sintesis UiO66 menggunakan pelarut DMF pada suhu $120{ }^{\circ} \mathrm{C}$ memiliki bentuk bulatan kecil yang bergerombol. Morfologi permukaan padatan UH (20) seperti ditunjukkan pada Gambar 3.c memiliki bentuk oktahedral dengan bagian luar ditutupi oleh bulatan kecil bergerombol. Morfologi ini memiliki kesamaan dengan padatan MOF biner yang telah dilakukan sebelumnya [5] memiliki bentuk oktahedral dengan bagian luar terdapat bulatan kecil bergerombol. Mikrograf UH (20) masih memperlihatkan bentuk oktahedral seperti HKUST1 namun tidak seseragam dan setajam padatan HKUST-1.

\section{KESIMPULAN}

Padatan HKUST-1, UiO-66, dan MOF biner UiO66/HKUST-1 telah berhasil disintesis pada penelitian ini menggunakan metode solvotermal secra one pot process. Keberhasilan sintesis pada penelitian ini dibuktikan dengan kesesuaian hasil karakterisasi dengan XRD, FTIR, dan SEM. Difraktogram padatan hasil sintesis memiliki puncak karakteristik pada $2 \theta=6,7^{\circ} ; 9,5^{\circ} ; 11^{\circ}, 54^{\circ}$; dan $19^{\circ}$ untuk padatan HKUST-1; $7,34^{\circ}, 8,3^{\circ}$ dan $25,6^{\circ}$ untuk padatan
UiO-66; $6,64^{\circ}, 7,18^{\circ}, 9,36^{\circ}, 11,5^{\circ}$ dan $18,9^{\circ}$ untuk padatan MOF biner. Spektra FTIR menunjukkan bahwa MOF biner hasil sintesis memiliki daerah serapan yang sama dengan padatan HKUST-1 dan UiO-66. Mikrograf HKUST-1 mmemiliki bentuk oktahedral, UiO-66 memiliki bentuk bulat bergerombol, dan UH (20) memiliki bentuk oktahedral dengan terdapat bulatan bergerombol di luar permukaan oktahedral.

\section{DAFTAR PUSTAKA}

[1] M. Ma, "Preparation and Characterization of Metal-Organic Frameworks for Biological Applications," 2011.

[2] Y.-R. Lee, J. Kim, and W.-S. Ahn, "Synthesis of metal-organic frameworks: A mini review," Korean J. Chem. Eng., vol. 30, no. 9 , pp. 1667-1680, Sep. 2013.

[3] M. Bosch, M. Zhang, and H.-C. Zhou, "Increasing the Stability of Metal-Organic Frameworks,” Adv. Chem., vol. 2014, pp. 1-8, Sep. 2014

[4] X. Liu, J. Luo, Y. Zhu, Y. Yang, and S. Yang, "Removal of methylene blue from aqueous solutions by an adsorbent based on metal-organic framework and polyoxometalate," J. Alloys Compd., vol. 648, no. 648, pp. 986-993, Nov. 2015.

[5] M. R. Azhar, H. R. Abid, H. Sun, V. Periasamy, M. O. Tadé, and S. Wang, "One-pot synthesis of binary metal organic frameworks (HKUST-1 and UiO-66) for enhanced adsorptive removal of water contaminants.," J. Colloid Interface Sci., vol. 490, pp. 685694, Mar. 2017.

[6] Y. Pan et al., "Core-Shell ZIF-8@ZIF-67-Derived CoP Nanoparticle-Embedded N-Doped Carbon Nanotube Hollow Polyhedron for Efficient Overall Water Splitting," J. Am. Chem. Soc., vol. 140, no. 7, pp. 2610-2618, Feb. 2018.

[7] P. Chowdhury, C. Bikkina, D. Meister, F. Dreisbach, and S. Gumma, "Comparison of adsorption isotherms on $\mathrm{Cu}-\mathrm{BTC}$ metal organic frameworks synthesized from different routes," Microporous Mesoporous Mater., vol. 117, no. 1-2, pp. 406-413, Jan. 2009.

[8] Y. Chen, X. Mu, E. Lester, and T. Wu, "High efficiency synthesis of HKUST-1 under mild conditions with high BET surface area and CO2 uptake capacity," Prog. Nat. Sci. Mater. Int., vol. 28, no. 5, pp. 584-589, Oct. 2018.

[9] F. Xu et al., "Ultrafast room temperature synthesis of GrO@HKUST-1 composites with high CO 2 adsorption capacity and CO 2 /N 2 adsorption selectivity," Chem. Eng. J., vol. 303, pp. 231-237, Nov. 2016.

[10] X. Zhu et al., "Inherent anchorages in UiO-66 nanoparticles for efficient capture of alendronate and its mediated release," Chem. Commun., vol. 50, no. 63, pp. 8779-8782, Jul. 2014. 